\title{
The Impact of Monetary Instruments in the Development of Monetary Policy in the Republic of Macedonia
}

\author{
Doc. Dr. Neritan Turkeshi \\ FON University, Skopje, R. Macedonia
}

\section{Doi:10.5901/ajis.2016.v5n3s1p539}

\begin{abstract}
In the function of accomplishment of the macroeconomic and monetary policy goals, the monetary authority, i.e. the central Banks in each country are competent to conduct a regulation of the monetary factors. While conducting the procedure of monetary regulation, the central bank uses different monetary instruments. The instruments of the monetary regulation although numerous, among themselves differ: as from the aspect of the time when their implementation began (historical aspect), also from the aspect of their impact over the process of monetary regulation. Having that a starting point, each country implements different instruments of monetary regulation, according to the specifics and characteristics of each country separately.
\end{abstract}

\section{Introduction}

In regard to the issue of the choice of instruments of monetary regulation, there are different, views and opinions in the monetary theory literature, which often are opposed. According to some theorists, the use of a large number of monetary instruments in modern developed market economies can only complicate the conditions, rather than helping in solving the problems. According to them, the effects of the implementation of one or another monetary instrument can be reduced and even abolish, with the same time use of another or more other instruments of the monetary policy. According to other representatives, the procedure of monetary regulation can be successfully conducted if it's implemented only one branched monetary instrument.

The decision which instruments will be used, in what time and with what intensity depends on the level of development of the economy, the phase of the economic cycle of the economy of one country, the level of monetarism, i.e. the level of development of the financial market, the characteristics of the financial system and the goals of the macroeconomic, and in those frames the goals of the monetary policy. In the countries with developed financial market, the process of monetary regulation is acting relatively fast and efficiently. In these countries it can be efficiently conducted the policy of monetary regulation, with one or more instruments of the monetary policy, due to which, in conditions of development, the actions of the monetary authority are transferred much faster and more efficiently among all the actors and institutions of the financial sector, and later on the other sectors in the frames of the national economy. It's totally different the approach, the impact and the effects in implementation of the monetary policy in the countries with insufficiently developed financial market. Those are countries with a lower level of economic development, with a lower level of monetarism, and countries with insufficient institutional capacities for implementation of the process of monetary regulation.

In the function of accomplishment of the macroeconomic and monetary goals, the Central Bank of the Republic of Macedonia in the period after the monetary independence until today uses numerous instruments of the monetary policy in order to efficiently regulate the monetary factors. The choice of the instruments of the monetary regulation (although different in separate time periods) was conditioned by numerous factors. As the most important factors which affected while choosing the instruments of the monetary regulation are:

- the insufficient level of development of the financial market;

- the great dependence of the commercial banks from the Central Bank. The loans of the Central Bank are very important source of funds to the commercial banks. On the other hand, part of the funds of the commercial banks, in the form of mandatory deposits, funds on the accounts of the commercial banks, the funds of the reserve fund of the commercial banks, are kept in Central Bank accounts;

- the common practice of crediting by the state, in the function of financing the deficit of the budget of state. It's about the crediting of the state by the Central Bank, independently from the monetary credit and economic 
movements, which implies to the insufficient level of independence of the central authority;

- relatively low level of the interests of the loans of Central Bank, which means that the funds of the primary emission were considered as a highly preferred additional source of financing the commercial banks. A basic criterion in deciding about the choice of the instruments of monetary regulation is the intent, i.e. the goals that want to be achieved in the process of monetary regulation. If it known that in the process of monetary regulation is covered the offer and demand of the monetary factors (offer and demand of money and loans), then the instruments of the monetary regulation are divided into:

- the instruments with which is regulated the offer of the monetary factors;

- $\quad$ the instruments with which is regulated the demand of the monetary factors.

According to the previous practice of the implementation of the instruments of monetary policy, the instruments of the monetary regulation are divided into two groups: the instruments with which is regulated the offer of money and instruments with which is regulated the demand of money.

\section{Basic Instruments of the Monetary Regulation}

In the monetary policy literature can be met a bigger number of classification of the instruments of monetary policy depending on the criteria which is used during their classification. Still, the most significant is the classification of the instruments of the monetary policy in:

- Instruments which regulate the offer of money;

- Instruments which regulate the demand of money.

Given the fact that the offer of money consists of numerous monetary aggregates, than is logical that in the process of regulation of each separate monetary aggregate to be conducted one or more instruments of the monetary policy. According to the previously stated, the instruments which regulate the offer of money are divided in ${ }^{1}$ :

a. Instruments for regulation of the primary money.

- crediting by the Central Bank;

- issuing obligations and treasury bills;

- $\quad$ buying and selling of хартии од вредност, as well as monetarism of the other financial forms of funds;

- buying and selling of foreign currencies.

b. Instruments for regulation of the monetary multiplier.

- determination and change of the rate of mandatory reserves of the commercial banks at the Central Bank;

- other mandatory deposits at the central bank.

c. Other instruments for regulation of the offer of loans.

- prescribing the minimal rates of liquidity of the commercial banks, as is the timely structure of the placements;

- limitation of the volume of the credit placements;

- inter-banking agreements for crediting.

The demand of money consists of the demand of cash and demand of loan funds, as two of the most important monetary factors. According to the structure of the demand of monetary factors, different instruments of the monetary policy are implemented, in the function of regulating the demand of money. In the group of the instruments which regulate the demand of money are:

a. The instruments which regulate the amount of cash in circulation;

b. The instruments which regulate the interest rate of the loans from the primary emission;

c. Prescribing the minimal general conditions for crediting by the borrowers.

Depending on whether the instruments of the monetary policy directly or indirectly affect the process of monetary regulation, the instruments of the monetary policy are divided in:

- Direct instruments of monetary regulation;

- Indirect instruments of monetary regulation.

The previous practice of the implementation of the instruments of monetary policy in function of regulation of the offer and demand of monetary factors implies that, the monetary authority in the country, specifically the Central Bank can successfully conducts its function of a regulator of the monetary trends. The function of the Central Bank in macro

1 Dr. Shaban Prevalla, Instruments of monetary regulation, Published in the weekly Business, 2006. 
plan is to regulate the credit potential, and through that the liquidity of the banking sector. Through the emission policy, i.e. through determining the quantum of the primary money, the Central Bank influences on the credit potential of the commercial banks, while through the monetary multiplication it regulates the amount of money in circulation.

\section{Direct Instruments of the Monetary Regulation}

Characteristically for the so-called direct instruments of the monetary regulation is the fact that although through them can be influenced directly on certain positions in the balance of the commercial banks (active and passive) in the process of monetary regulation, still their use in the process of monetary regulation does not bring a change in the active and the passive of the balance of the Central Bank.

The frequently used instrument from this group of instruments is the limitation of the placement of commercial banks. This instrument is used in practice only if with the indirect instruments of the monetary regulation was not achieved the scheduled goal, i.e. the regulation of the amount of money in circulation. Given the fact that the long term use of this monetary instrument causes multiple negative implications, its use is only possible in rare cases, i.e. when measures for quick and efficient reaction of the monetary authority are needed, with the aim to overcome the serious distortions of the monetary trends. The effects of the long term use of this instrument are reflected in:

- It discourages, i.e. dissimulate the savings;

- It causes moving of the capital from the banking sector;

- It limits the competition in the banking sector;

- It leads to incorrect allocation of the resources.

The long term use of this instrument of monetary regulation can bring to the regulation of the monetary trends, but the negative implications of its long term use, even more complicate the condition. This long use of the instrument directly reflects on the level of savings, and through that on the credit potential of the commercial banks. From those reasons, the use of this instrument can only be a temporary solution, and that is in conditions of significant distortions of the monetary trends, when fast and efficient changes of the monetary trends are needed. This instrument was used in the past in the function of monetary regulation, as one of the qualitative instruments of monetary policy.

\section{Indirect Instruments of the Monetary Regulation}

Beside the direct instruments of the monetary regulation, the NBRM also uses indirect instruments of monetary regulation. Through these instruments, the NBRM acts in regulation of the monetary offer. In that process of regulation it comes to certain changes in the positions of the active and the passive of the NB, which changes enable creation of primary money, or they cause changes which request implementation of a procedure of withdrawal of the surplus money in circulation. In the group of the indirect instruments of the monetary regulation are:

- refinancing of the commercial banks through the so-called rediscount loans;

- buying and selling of deposits in auction;

- auction of treasury bills;

- determining the mandatory reserve;

- determining the minimal rate of liquidity;

- interest policy.

\subsubsection{Refinance of the commercial bans through the so-called rediscount loans}

Refinance of the banks through the rediscount loans, beside the fact that it belongs to the group of the so-called market instruments of monetary regulation, by the end of 1993 was used as the only instrument of monetary regulation in our country. Through the process of refinancing of the commercial banks with the so-called rediscount loans, the NBRM essentially makes a direct regulation of the monetary trends and through them in indirect way affects on the monetary aggregate M1. Through the use of this instrument, the NBRM succeeded to:

- Neutralize the monetary effects from the foreign currencies transactions and in that way to maintain the exchange rate of the denar; 
- Accomplish the selective function of the monetary policy, i.e. to influence in directing the loans of the banks in financing certain priority projects.

The essence of this indirect instrument of monetary regulation consists on the fact that the NBRM was conducting rediscounting of the loans which the commercial banks would have approved to the final beneficiaries for certain purposes, which were defined with a Decision of the Assembly of the Republic of Macedonia and in function of accomplishment of the selective monetary-credit policy. But, due to the great fluctuations in demand of money for prioritized purposes, it happened often that a huge discrepancy would appear between the increased needs and the possibilities for financing. Such a discrepancy was amortized through the mechanism of limitation of the possibilities for rediscounting the loans that the banks have approved for those purposes. Quotes were determined, foe every quarter, as the maximal possible frames to which the banks were able to the refinance the loans approved to the final beneficiaries.

The use of the rediscount loans as an instrument of the selective monetary policy continued until April of 1994 when this instrument of monetary regulation was abolished. The reason for this abolish of the so-called selective monetary placements consists of the fact that the rediscount loans turned into ineffective instrument of monetary regulation which was also shown in practice. Most often, this instrument of monetary policy was used to finance projects in the area of agriculture and livestock.

\subsubsection{Auction of treasury bills}

The NBRM started with auctions of treasury bills in February of 1994, and that meant a beginning of implementation of one of the basic instruments of the monetary policy, the so-called operations of open market. This instrument of monetary policy is considered as flexible, markedly oriented and quite efficient instrument of monetary regulation.

Contrary to the auction of deposits, which are conducted on regular (daily) basis, the auction of treasury bills is conducted on request, respectively a call from the NBRM. A right to participate in the auction of treasury bills has all registered commercial banks, while the savings banks has a right to participate in these auctions only indirectly, i.e. through the banks. The participation of the commercial banks in auction is confirmed with their offer. If the offer of the commercial banks is accepted, then the commercial bank is obliged to pay the price stated in its offer. The period of maturity of the treasury bills can on 7, 15, 30, 60, 90, 120, 150 and 180 days. But, the commercial banks can submit them for payment at the NBRM also prior to their period of maturity. The commercial banks can use the bough treasury bills also as collateral to gain the so0called Lombard loans from the NBRM. Also, the NBRM can initiate buying of the previously sold treasury bills before the period of their maturity, if the NBRM evaluates that its intervention is needed in the function of increasing the amount of money in circulation.

\subsubsection{Determining the mandatory reserve}

The mandatory reserves apply as a very important instrument in the process of monetary regulation. When using the mandatory reserves as instrument in function of the monetary regulation, the amount of the rate of mandatory reserves is from a great importance. In the moment of monetary independence of the Republic of Macedonia, the rate of mandatory reserves was placed on a very high level and it was $27.2 \%$. Such a high level of placement of the rate of mandatory reserves was conducted with the aim to keep (maintain) the price stability through the regulation of the offer of monetary factors. Later it was approached toward gradual decrease of the rate of mandatory reserves, the first decrease was conducted in June 1992, and then two more times until the end of 1992. The first decrease of the rates of mandatory reserves in 1993 was conducted in June, when the rate of mandatory reserves of demand deposits and time deposits up to three months decreased from $15,0 \%$ to $12,0 \%$, while the rate of mandatory reserves of the other types of deposits remained unchanged. Such a decrease of the rate of mandatory reserves brought an increase of the liquidity of the banking sector for 80 million denars ${ }^{3}$. The second decrease of the rates of mandatory reserves followed in September, and the third in November of the same year. If the is added to that, than we can easily detect the points and the reasons of the increase of liquidity of the banking sector. But, the decrease of the rates of mandatory reserves, as well as the abolition of the obligation of separating the mandatory reserves of deposits of the sociopolitical communities, even more increased the liquidity of the banking sector in the country, which created the basis for implementation of more relaxed monetary policy, although such procedures brought in question the maintenance of the price stability in the country. 


\section{Conclusion}

Highest monetary authority in all modern organized states are their central banks, while in our country the role of the Central bank after the monetary independence has the National Bank of Republic of Macedonia. The main goal (ultimate goal) of each monetary authority, and therefore the NBRM is to maintain the price stability as one of the basic prerequisites for ensuring macroeconomic stability;

Monetary policy, as part of the overall macroeconomic policy of one country has a great impact on the overall socio-economic and social development, and in this framework and the development of the banking sector of a country;

The impact of the monetary policy on the changes of real economic flows on one hand, and the impact on the stability of the financial system, and thus the monetary flows, on the other hand, is in the function of stimulating the overall economic and social development, and within this framework the development of the banking sector. Through the application of measures and instruments of the monetary policy it seeks to sustain the price stability as the ultimate goal of monetary policy, while through the mechanism of monetary regulation, the stability of the purchasing power of money in the internal market and exchange rate stability of the national currency.

\section{References}

Dr. Shaban Prevalla and MA Savo Ashtalkovski "Monetary economy", Skopje, 2006.

Dr.Neritan Turkeshi "The role of the monetary policy and the banking sector in the development of the Republic of Macedonia", FON University, Skopje, 2014.

Ducker, J. Michael, Can nominal GDP Targeting Rules Stabilize Economy? The Federal Reserve Bank of St. Louis, June 1993.

Dr. G. Bishev, MA Tome N., Financial order and banks, NAAM-Skopje, 1995.

www.WorldBank.org/ieg

Prof.Dr.Baki Koleci and Doc.Dr Neritan Turkeshi "Management", FON University, FON, Skopje, 2014.

Wender, McGowan , "International financing", California State Universiuty, Long Beach, viti 1987.

Yellen, Janet, "The Job's Not Done Yet", New York Times, july 1997, pg.29.

Doc.Dr.Neritan Turkeshi "Brend Menagment", FON University, Skopje, 2014. 